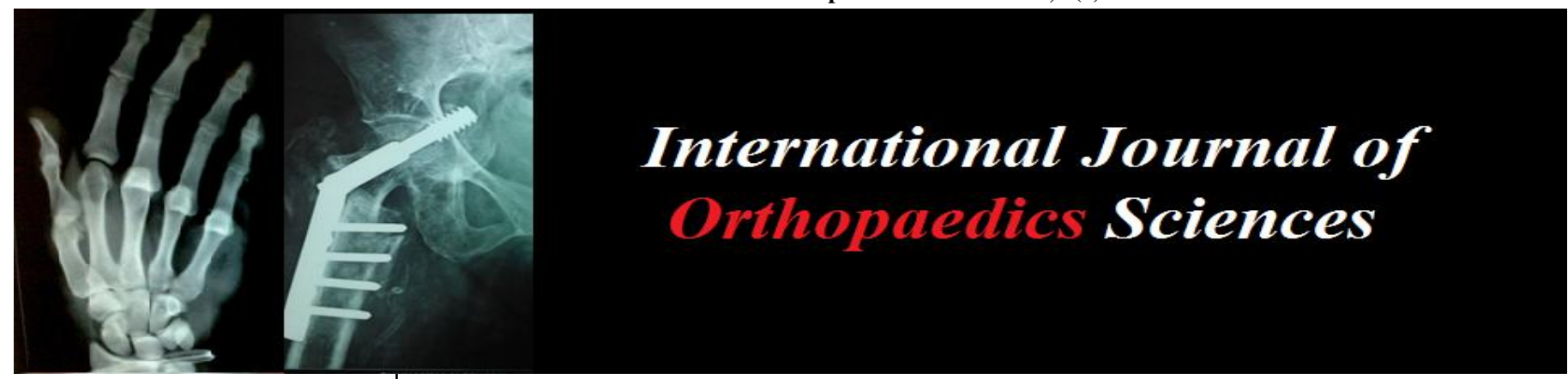

E-ISSN: 2395-1958

P-ISSN: 2706-6630

IJOS 2020; 6(1): 1027-1029

(C) $2020 \mathrm{IJOS}$

www.orthopaper.com

Received: 16-11-2019

Accepted: 20-12-2019

\section{Prasanna Chandiralingam}

Associate Professor of

Orhtopaedics, PSG Hospitals,

Peelamedu, Coimbatore,

Tamil Nadu, India

\section{Sri Divya K}

In-charge Medical Officer, Government Upgraded PHC

SS Kulam, Coimbatore, Tamil Nadu, India
Corresponding Author: Prasanna Chandiralingam Associate Professor of Orhtopaedics, PSG Hospitals, Peelamedu, Coimbatore,

Tamil Nadu, India
Original Article:

\section{Low back pain in pregnancy: Prevalence among south Indian population}

\section{Prasanna Chandiralingam and Sri Divya K}

DOI: https://doi.org/10.22271/ortho.2020.v6.i1m.1953

Abstract

Females during pregnancy commonly encounter back pain at some point of time. Unfortunately, this symptom is quiet carried away and often neglected by the health care providers. Low back pain in pregnancy can have a significant impact both psychologically and physiologically as well. In the present study we intended to find out the prevalence rate for this symptom among the South Indian population by formulating a questionnaire proforma.

There was a $27.82 \%$ prevalence rate for low back pain in our study. Though we did not differentiate the back pain as lumbar pain and pelvic girdle pain, quiet a majority of the patients $(40 \%)$ were facing mild to moderate disabilities because of the pain. The mean duration at the onset of the symptoms was 26 weeks of pregnancy. The mean age of the patients with low back pain was 26 years.

Identification of the back pain symptoms during pregnancy is needed so as to assess and provide proper management to such patients.

Keywords: Low back pain, pregnancy, prevalence, disability

\section{Introduction}

Low back pain (LBP) is a commonly encountered symptom from pregnant females. Studies have estimated that LBP is prevalent in about $50 \%$ of females at some point of time during pregnancy ${ }^{[1,2]}$. Although it is confined to the pelvic area and not so harmful to the females or their foetuses, it is quiet a disabling symptom ${ }^{[3,4]}$. LBP is said to cause moderate disability and about $10 \%$ of patients will take off time from work ${ }^{[5,6]}$. Back pain in pregnancy is due to various factors, such as mechanical, hormonal and others ${ }^{[1,2,7-9]}$.

In the present study we tried to figure out the prevalence of LBP among the south Indian population, attending a primary health care.

\section{Materials and Methods}

The aim of this study was to determine the prevalence of LBP among the pregnant females. The study was conducted at a government primary health centre, Southern India, from January 2018 to December 2018. A proforma (fig.1) was created and data collected accordingly among all patients attending the antenatal clinic. A total of 488 patients data were collected during this period.

All the patients who were attending the antenatal clinic for the first time at the time of registration of their pregnancy were included in the study. Those patients who were in their subsequent visits at the time of initiation of this study were excluded because of the chances of error in calculations, as majority of the patients were not able to recollect an episode of LBP at their previous visits.

Apart from the patient's demographic profile, the first leading question was 'whether you have any type of back pain?' If the answer was 'No', further data's were skipped and if the answer was 'yes', the proforma was completed. The patients were subsequently followed-up until the time of delivery and if the patient had a symptom of LBP at any point of time, the proforma was completed at that time.

Patients who had LBP prior to the present pregnancy were excluded from the study. Similarly patients who had pre-existing organic pathology (intervertebral disc prolapse, spondylolisthesis, etc.,) that may contribute to LBP and patients who had a recent history of trauma to the back were also excluded from the study. 


\begin{tabular}{|l|l|l|l|}
\hline S. No. & \multicolumn{2}{|c|}{ Patient's Demographic Profile } \\
\hline 1. & Name & & \\
\hline 2. & Age & & \\
\hline 3. & GPLA & & \\
\hline 1. & Weight and height & Yes & No \\
\hline 5. & Address & & \\
\hline \multicolumn{1}{|c|}{ LBP specific Questionnaire } & \\
\hline S.No. & \multicolumn{1}{|c|}{ Questions } & & \\
\hline 1. & Whether you have LBP? & & \\
\hline 2. & Any previous history of (H/O) LBP? & & \\
\hline 3. & H/O any recent trauma? & & \\
\hline 4. & Is the present pregnancy a multiple pregnancy (Twins or Triplets)? & \\
\hline 5. & Does the patient suffering from polyhydramnios? & \\
\hline 6. & H/O any spinal anaesthesia in the past? & \\
\hline 7. & Whether the weight gain is appropriate for the gestational age? & \\
\hline 8. & Duration of pregnancy at the onset of present symptoms(in weeks) & \\
\hline G: gravida; P: parity; L: no. Of living children; A: no. of abortions & \\
\hline
\end{tabular}

Fig 1: The questionnaire proforma used in the study

\section{Results and Discussion}

Data was collected for a total of 478 patients during the study period. 16 patients had a pre-existing history of back pain prior to the present pregnancy. The LBP was either a pain during menstruation or an on and off back pain of undiagnosed causes. All of these 16 cases were excluded from the study. One patient with complaint of LBP at 8 weeks of pregnancy had a history of trivial fall prior to the presentation and hence was excluded from the study. Another patient who was a multiparous woman in her third pregnancy had spondylolisthesis at L5-S1 level. Though she had no complaints of LBP during the previous two pregnancies, she was also excluded from the study. Hence a total of 460 patient's data was used to analyse the results.

A total of 128 patients were having LBP out of the 460 cases. That worked out a prevalence rate of $27.82 \%$. This prevalence was quiet low as compared to other studies from African ${ }^{[10]}$ and Western ${ }^{[11]}$ population who had prevalence of more than $50 \%$. LBP prevalence among Nepalese women was $34 \%$ in a study ${ }^{[12]}$ and was bit closer to that of our study. LBP in pregnancy has been predominantly classified [13, 14] into 2 types: lumbar pain (LP) and pelvic girdle pain (PGP) or posterior pelvic pain (PPP). LP is defined as pain between the twelfth rib and the gluteal fold, while PGP is defined as pain experienced between the sacroiliac joint and the gluteal fold, or in the pubic symphysis ${ }^{[15]}$. We in the present study did not differentiate between the two types and all patients were classified to be suffering from LBP.

About $40 \%$ of our patients (52/128) who had LBP were facing mild to moderate amount of disabilities. The natures of disabilities were mainly in the form of handling the first child and in doing household chores like fetching water. Though there was some sort of disability only 2 out of these 52 cases had severe enough pain so as to have consulted a specialist for treatment. These 2 were working women and they never took any leave from their work for the LBP. In a study by Wang et $a l^{[5]}$. their disability rate was around $60 \%$.

Of the 460 patients in our study, a majority of them (320) were housewives and the remaining 140 were working women. 92 of them were doing constructional or household works in other homes and 48 were office going. 104 cases among the housewives had LBP, whereas 24 among the working group had LBP. The results are summarised in the table 1 .

Table 1: Prevalence of LBP with regard to occupation

\begin{tabular}{|c|c|c|c|c|}
\hline \multicolumn{2}{|c|}{ Patients } & Number & With complaints of LBP (No.) & Prevalance (\%) \\
\hline \multicolumn{2}{|c|}{ Total cases } & 460 & & \\
\hline \multicolumn{2}{|c|}{ Housewives } & 320 & 104 & 32.5 \\
\hline \multirow{2}{*}{ Working women } & Manual work & 92 & 22 & 23.91 \\
\cline { 2 - 5 } & Office work & 48 & 2 & 4.16 \\
\hline
\end{tabular}

A total of 184 cases were in their first pregnancy, out of which 32 of them complained of LBP $(17.39 \%)$. The remaining 276 cases were either $2^{\text {nd }}$ or $3^{\text {rd }}$ time pregnant. 92 of them had LBP (34.78\%). This trend was similar to literature which states that the prevalence of LBP increases with parity ${ }^{[16]}$.

There was one case of twin pregnancy and 3 cases of polyhydramnios, but none of the 4 patients had LBP. The mean age of the patients with LBP was 26 years. The mean duration at the onset of symptoms was 26 weeks ( 8 to 34 weeks) towards the later part of second trimester. The mean duration at onset of pain was 24 weeks in Nepalese women [12].

LBP typically tends to begin as early as 18 weeks of pregnancy and may persist in the postpartum period for as long as 15 months ${ }^{[17,18]}$. We in our study did not study the pattern of LBP and patients were not followed up in the postpartum period.

LBP in pregnancy is often regarded as harmless and quiet commonly ignored by the health care professionals ${ }^{[19]}$. But they have been reported to have some serious negative psychological effects in various studies ${ }^{[19-21]}$. Therefore a lack of awareness of this predominant complaint from pregnant women can lead to poor management of such cases. The commonly reported risk factors for pregnancy related back pain are high strenuous workload, frequent or prolonged torso flexion, previous history of LBP, previous history of any trauma to the pelvis ${ }^{[15,22,23]}$, body mass index (BMI), and parity. Though, in the present study we did not try to find out the risk factors or their causal relationship. We just tried to make out the magnitude of the problem.

The prevalence rates are influenced by the perception of pain among the various group of population. Also we did not consider the various risk factors involved like BMI. A 
detailed questioner involving all the risk factors and other indicators of pain like the visual analog scale (VAS) would have been a good indicator of actual prevalence. The socioeconomic status of the patient was also not included in the present study, which was another drawback of the study.

\section{Conclusion}

'Back pain' as a complaint from a pregnant woman is often regarded as harmless and a common complaint. But the high prevalence of this complaint and the implications it have in a pregnant females necessitates a proper diagnosis and management.

\section{References}

1. Vleeming A, Albert HB, Ostgaard HC, Sturesson B, Stuge B. European guidelines for the diagnosis and treatment of pelvic girdle pain. Eur Spine J. 2008; 17:794-819.

2. Perkins J, Hammer RL, Loubert PV. Identification and management of pregnancy related low back pain. J Nurse Midwifery. 1998; 43:331-340.

3. Kanakaris NK, Roberts CS, Giannoudis PV. Pregnancyrelated pelvic girdle pain: an update. BMC Med. 2011; 9:15.

4. Elden H, Lundgren I, Robertson E. Life's pregnant pause of pain: pregnant women's experiences of pelvic girdle pain related to daily life: a Swedish interview study. Sex Reprod Healthc. 2013; 4(1):29-34.

5. Wang SM, Dezinno P, Maranets I, Berman MR, Caldwell-Andrews AA, Kain ZN. Low back pain during pregnancy: prevalence, risk factors, and outcomes. Obstet Gynecol. 2004; 104(1):65-70.

6. Kristiansson P, Svardsudd K, von Schoultz B. Back pain during pregnancy: a prospective study. Spine (Phila $\mathrm{Pa}$ 1976). 1996; 21(6):702-709.

7. Van Dongen PW, de Boer M, Lemmens WA, Theron GB. Hypermobility and peripartum pelvic pain syndrome in pregnant South African women. Eur J Obstet Gynecol Reprod Biol. 1999; 84:77-82.

8. Stuge B, Hilde G, Vollestad N. Physical therapy for pregnancyrelated low back and pelvic pain: a systematic review. Acta Obstet Gynecol Scand. 2003; 82: 983-990.

9. Sabino J, Grauer JN. Pregnancy and low back pain. Curr Rev Musculoskelet Med. 2008; 1:137-141.

10. Ayanniyi O, Sanya AO, Ogunlade SO, Oni-Orisan MO. Prevalence and pattern of back pain among pregnant women attending ante-natal clinics in selected health care facilities. African Journal of Biomedical Research. 2006; 9:149-56.

11. Mantle MJ, Greewood RM, Currey HLF. Backache in pregnancy. Rheumatism and Rehabilitation, 1997, 95101.

12. Ranjeeta Shijagurumayum Acharya et al. Prevalence and severity of low back- and pelvic girdle pain in pregnant Nepalese women. BMC Pregnancy and childbirth. 2019; 19:247.

13. Kristiansson P, Svardsudd K, Von Schooltz B. Back pain during pregnancy. A prospective study. Spine. 1996; 21:702-709.

14. Noren L, Ostgaard S, Nielsen TF, Ostgaard NC. Reduction of Sickleave for Lumber back and posterior pelvic pain in pregnancy. Spine. 1997; 22:2157-60.

15. Vleeming A, Albert HB, Östgaard HC, Sturesson B, Stuge B. European guidelines for the diagnosis and treatment of pelvic girdle pain. Eur Spine J. 2008;
17(6):794-819.

16. Mogren IM, Pohjanen AI. Low back pain and pelvic pain during pregnancy: prevalence and risk factors. Spine. 2005; 30:983-91.

17. Wu WH, Meijer OG, Uegaki K, Mens JM, van Dieen JH, Wuisman PI et al. Pregnancy related pelvic girdle pain (PPP), I: Terminology, clinical presentation, and prevalence Eur Spine J. 2004; 13(7):575-89.

18. Sjodahl J, Gutke A, Oberg B. Predictors for long-term disability in women with persistent postpartum pelvic girdle pain. Eur Spine J. 2013; 22(7):1665-73.

19. Gutke A, Boissonnault J, Brook G, Stuge B. The severity and impact of pelvic girdle pain and low-back pain in pregnancy: a multinational study. J Women's Health. 2018; 27(4):510-7.

20. Mackenzie J, Murray E, Lusher J. Women's experiences of pregnancy related pelvic girdle pain: a systematic review. Midwifery. 2018; 56:102-11.

21. Mens JMA, Huis in't Veld YH, Pool-Goudzwaard A. Severity of signs and symptoms in lumbopelvic pain during pregnancy. Mant Ther. 2012; 17:175-79.

22. Wu WH, Meijer OG, Uegaki K, Mens JM, van Dieen JH, Wuisman PI, Ostgaard HC. Pregnancy-related pelvic girdle pain (PPP), I: terminology, clinical presentation, and prevalence. Eur Spine J. 2004; 13(7):575-89.

23. Juhl M, Andersen PK, Olsen J, Andersen A-MN. Psychosocial and physical work environment and risk of pelvic pain in pregnancy. A study within the Danish national birth cohort. J Epidemiol Community Health. 2005; 59(7):580-5. 